\title{
Assessment of the Social, Economic and Environmental Aspects of Solid Waste Management in Selected Open Dumpsites in Kenya
}

\author{
Kenneth Kamumbu Mugo ${ }^{1}$, James Muraya Gichanga ${ }^{2}$, Gatebe Erastus ${ }^{2}$ and Paul Mwangi Njogu ${ }^{1}$ \\ 1. Institute of Energy and Environmental Technology (IEET), Jomo Kenyatta University of Agriculture and Technology (JKUAT), \\ Nairobi 00100, Kenya \\ 2. Department of Chemistry, Jomo Kenyatta University of Agriculture and Technology (JKUAT), Nairobi 00100, Kenya
}

\begin{abstract}
The most prevalent way of disposing solid waste in most of the developing countries is open dumping which is the easiest and considered to be the cheapest method of removing waste from the immediate environment. The increasing awareness on public health and environment quality concerns are expected to provide the impetus that is needed to develop and implement a sustainable approach to manage solids. An inventory of these locations, the types of waste handled and management processes for waste products will aid in the assessment of the polluting capability of such sites. This paper discusses research experiences gathered during a study that was undertaken in three Kenya dumpsites to explore the potential for utilising the waste for energy generation in a low-income economy and at the same time, address worsening disposal challenges.
\end{abstract}

Key words: Solid waste, dumpsites, management.

\section{Introduction}

Municipal solid waste management is an important part of the urban infrastructure that ensures the protection of environment and human health. Environmental pollution from uncontrolled solid waste disposal is of major concern and generates chemicals or pollutants that reach their surroundings, such as soil, groundwater resources, and even the ambient air, because of environmentally unacceptable disposal or failure of lining system in the dumpsites [1].

Increasing amount of waste emanating from residential, commercial and industrial areas, together with changing nature of waste over time, have led to the degradation of the quality of the environment [2].

The placement of solid waste in dumpsites is the most prevalent form of ultimate waste disposal.

If control is lacking or inadequate, disposal

Corresponding author: Kamumbu Kamumbu Mugo, Ph.D., research fields: environmental technology, MSC environment legislation and management and BSC civil engineering. E-mail: kkamumbu@yahoo.com. facilities may become point sources of groundwater contamination. In many regions, centralised waste disposal has historically occurred by land filling, wherein local quarries and gravel pits have been filled with waste because, in many cases, they simply constituted an appropriately sized hole in the ground $[1,3]$. Such locations typically offered little protection against contamination of adjacent groundwater supplies. Although created for the opposite effect, burying trash in a dumpsites causes contamination to the environment because they contaminate watercourses, groundwater, and they pollute the air with gasses produced by the dumpsites. When rainfall soaks into waste in a garbage tip, it slowly drains through the waste under gravity.

The processes of storage, collection, transport, treatment and disposal of wastes all have the potential to pollute the environment and particularly groundwater due to uncontrolled migration of fluids (leachate) derived from the wastes [4].

Any site where waste is concentrated, processed 
(recycled) and stored even for a short period of time, may be a potential point source of groundwater contamination. Such processing facilities are often not well regulated or licensed and frequently occur in urban or semi-urban settings, where local water supply points may be impacted by these activities.

Hazardous and non-hazardous wastes are differentiated in waste management legislation of many countries [5]. A range of legal definitions exist for hazardous waste, but it can generally be thought of as waste or a combination of wastes with the capacity to impair human health or the environment due to its quantity, concentration, or physical, chemical or infectious characteristics when improperly used, treated, stored, transported or disposed.

Where uncontrolled open dumps are common, all waste tends to be dumped together, regardless of its origins or its hazardous nature. A specific characteristic of leachate from hazardous industrial waste is that it may be toxic to the bacteria naturally present and thus, delay biodegradation of organic substances in leachate [3].

The health risk and the effect on the quality of livelihood caused by this practice calls for comprehensive approach to the assessment of the impact of waste dumpsites on the environment.

In recent years, stringent legislation has been introduced for systematic and planned waste development ensuring minimum damage to environment [6]. With growing environmental awareness, the subject of waste management in a cost effective and eco-friendly perspective is gaining foot for protection of environment and derivation of value added wealth from waste.

Management of waste creates values ethical and aesthetic in nature $[7,8]$. It is beneficial from pollution control point of view and even generates revenue. Beneficiations and recycling of waste products can cater to the needs of the consumer sector. In this competitive industrial age, the aspect of waste control is of paramount importance.
Available area and volume inside the existing dump yards and estimated capacity of future dump-site are not fully known [9]. It is felt that lack of well-defined organizational structure (considering solid waste management as an independent function), and adequate data base for decision-making are by far the most important factors for proper solid waste management. Reduction in generation of waste and gainful utilization and recycling of these wastes not only improve the economics of operation but also prevent degradation of the ambient environment [10]. Therefore, it is essential to study all these waste prior to their processing for converting them to value added wealth in one form or other. Possible recovery of valuables from some of them and means of their optimum utilization is essential. With appropriate segregation and recycling system, significant quantity of waste can be diverted from landfills and converted into resource.

In urban areas, especially in the rapid urbanising cities of the developing world, problems and issues of solid waste are of immediate importance. However, rapid population growth overwhelms the capacity of most local authorities to provide even the most basic services [11, 12].

Solid waste management encompasses generation, collection, transportation and disposal of urban waste. Urban authorities have the responsibility to ensure safe, reliable and cost effective removal and disposal of solid waste, which takes up a large proportion of available resources that are not adequate to cope with the magnitude of the problem [13]. However, the management varies, in most urban areas. Garbage is collected either by a government agency or private contractor, and this constitutes a basic and expected government function in the developed world $[8,14]$.

Indeed, the overall problem of MSW is multi-faceted: many organizations, including the United Nations (UN) and various Non-Governmental Organizations (NGOs) advocate for an integrated approach to MSW management by identifying key 
stakeholders, identifying specific issues which comprise important "stumbling blocks", and making recommendations based on appropriate technologies, local information, and pressing human and environmental health concerns [7].

Objective: To assess the social, economic and environmental aspects of solid waste management in selected open dumpsites in Kenya.

\section{Material and Methods}

This study focuses mainly on solid waste management under the jurisdiction of Nakuru, Nyeri and Nairobi counties. Variable data and information was gathered during consultations with waste managers and policy makers. Instruments used included an interview guide and a field observation guide. The collected information was analyzed to develop an understanding of the existing solid waste management system and its drawbacks.

\section{Results and Observation}

The waste management issue in Kenya is as a result of many interconnected factors. Inadequate infrastructural waste management facilities such as treatment and disposal infrastructure, unreliable and irregular waste collection patterns lead to littering and physical accumulation of solid waste. The absence of modern waste management facilities such as sanitary landfills has left open dumping as the only means of disposal for solid waste. Lack of garbage segregation at the source worsens the situation. This poses great risks to human health while reducing recycling potentials to generate by-products.

Informal sector waste entrepreneurs and individuals sort and collect recyclable materials from dumpsites. The study established that they are connected to the international commodities marketplace through the materials they collect. Ultimately, the economic value and profit potential of the waste materials is connected to international commodity prices, global trade, and industrial policy. Partnerships involving informal sector operators depend on their ability either to use the collected materials for their own manufacturing, or to prepare materials for commercial use.

Waste was found indiscriminately dumped on the ground surface, without any compaction effort and all the waste piles have undergone some degree of heavy burning as a result of no soil cover, the long dry season, and random fires. The sites survey indicated that accessibility problems during the rainy season had necessitated the need for alternate illegal disposal areas.

The open air dumping of solid wastes at the dumping locations, besides causing aesthetic problems and nuisance due to nauseating pungent odor, also promotes spreading of disease by the disease vectors such as flies, mosquitoes and rats etc. The situation is further aggravated by the indiscriminate disposal of hazardous hospital and clinical wastes in the roadside bins and dumpsters.

Based on the condition of the waste mass visible during the field work, there was likelihood of potential landfill gas capture for beneficial use. However, a thorough subsurface waste investigation was necessary to verify waste limits, depth, composition and volume for possible dumpsite utilization. The possibility of expanding the footprint of dumpsites with any new and improved waste operations methodology is a key to the economic and environmental advantages.

Solid waste collection in Kenya generally serves only a limited part of the urban population. Majority of the people especially in slum areas remain without waste collection services. These are usually the low-income earners living in poor conditions in peri-urban areas.

Operational inefficiencies are due to inefficient institutional structures, inefficient organizational procedures, or deficient management capacity of the institutions involved as well as the use of inappropriate technologies.

The used vehicles are sophisticated, expensive and difficult to operate and maintain. These include waste 
amounts and composition, access to waste for collection, awareness and attitudes. Domestic waste from industrialized countries has a high content of packaging made of paper, plastic, glass and metal, and so, the waste has a low density. These factors make the waste very dense (high weight per unit volume). The consequences of this high density are that vehicles and systems that operate well with low-density wastes are not suitable or reliable when the wastes are heavy. The combination of extra weight and the corrosiveness caused by the water content cause rapid deterioration of equipment.

Many sources of waste might only be reached by roads, which are inaccessible because of their width, slope, congestion or surface. This is especially critical in unplanned settlements such as slums or low-income areas.

\section{Conclusion}

Waste generation and management is challenge in Kenya and developing countries. There are no practical methods or mechanisms available at sites for the safe disposal or treatment of hazardous wastes. Biodegradable and recyclable waste is underutilized making dumpsites potential source of economic exploitation. Many investments are required for existing and future waste related needs. Additionally, accurate technical consultancy, development of policies and professional design works are highly required overcome existing obstacles.

Few county governments have a dedicated income stream for solid waste services. Given the large number of individual issues and specific problems, it would seem tempting to address individual issues as they arise and apply local fixes, so as to keep collection and disposal services operating continuously as efficiently as possible. Indeed, in the short term, this is likely to be a good approach. In considering the long term, however, it is apparent from the scope of problems and the external factors brought to bear upon counties that a broader, more integrated set of solutions will be necessary in order to adequately address waste management.

\section{References}

[1] Akuffo, F. O. 1998. “Options for Ghana’s Power Needs: Renewable Energy Sources (1).” High Street Journal 12 (Jul.): 24.

[2] Kreith, F. 1994. Hand Book of Municipal Solid Waste Management. New York: McGraw-Hill Inc..

[3] California Energy Commission. 2000. "Municipal Solid Waste Power Plants.” Accessed April 22, 2002. http://www.energy.ca.gov/development/biomass/msw.ht ml.

[4] Fobil, J. N. 2001. "Factors to be considered in the Design of an Integrated Municipal Solid Waste Management in the Accra Metropolis." Master thesis, University of Ghana.

[5] Fobil, J. N., Carboo, D., and Armah Gourlay, K. A. 1992. World of Waste: Dilemmas of Industrial Development. Worcester: Billings \& Sons Ltd..

[6] Baird, C. 2000. Environmental Chemistry. New York: Freeman W. H. \& Co..

[7] Brigwater, A. V., and Boocock, D. G. B. 1997. Development in Thermo-Chemical Biomass Conversion. London: Blackie Academy \& Professional.

[8] Carboo, D., and Fobil, J. N. 2004. "Physico-Chemical Analysis of Municipal Solid Waste (MSW) in the Accra Metropolis.” West African Journal of Applied Ecology 5 (2): 116-117.

[9] Fobil, J. N., and Atuguba, R. A. 2004. "Ghana: Migration and the African Urban Complex.” In Globalization and Urbanization in Africa, edited by Falola, T., and Salm, S. J. Ghana: Africa World.

[10] Trenton, N. J., Fobil, J. N., Carboo, D., and Clement, C. 2002. "Defining Options for Integrated Management of Municipal Solid Waste in Large Cities of Low-Income Economies: The Case of the Accra Metropolis in Ghana.” The Journal of Solid Waste Technology and Management 12 (8): 106-117.

[11] Hankohl, J., and Kristiansen, T. 1996. Waste Incineration. Copenhagen: World Health Organization, Regional Office for Europe.

[12] IAEA. 1991. "Electricity and the Environment." In Proceedings of the Senior Expect Symposium, 31-85.

[13] Lomborg, B. 2004. Global Crisis, Global Solutions. UK: Cambridge University Press.

[14] Songsore, J., and Goldstein, G. 1995. "Health and Environmental Analysis for Decision-Making (Headlamp) Field in Accra." World Health Statistics Quarterly Journal 48: 10-34. 